\title{
El discurso sexista en los artículos de opinión. (Del masculino genérico, de los desdoblamientos morfológicos y de las duplicidades léxicas) ${ }^{1}$
}

\section{Sexist discourse in opinion articles. (Generic masculine, morphological double marking, and lexical doublets)}

José Joaquín Martínez Egido

Universidad de Alicante, Alicante, España

jj.martinez@ua.es

ACCESO ABIERTO / OPEN ACCESS

Cita: Martínez Egido, José Joaquín (2020). El discurso sexista en los artículos de opinión. (Del masculino genérico, de los desdoblamientos morfológicos y de las duplicidades léxicas). Textos en Proceso, 6(2), pp. 91-106.

https://doi.org/10.17710/tep.2020.6. 2.7jimartinez

Editoras: Susana Guerrero Salazar y Carmen Marimón Llorca

Recibido: 10/10/2020

Aceptado: 02/11/2020

Conflicto de intereses: El autor ha declarado que no posee conflicto de intereses.

Copyright: @ José Joaquín Martínez Egido. Esta obra está bajo licencia Creative Commons Reconocimiento 4.0

\section{Resumen}

El discurso sexista es un tema recurrente en los artículos de opinión y en las columnas de la prensa española, pues es un asunto polémico y portador claro de ideología. El objetivo de este trabajo, bajo la óptica del análisis metalingüístico de los textos, ha sido identificar el tratamiento y la postura de los articulistas en la prensa española ante el discurso sexista; concretamente en lo relativo al masculino genérico, a los desdoblamientos morfológicos y a las duplicidades léxicas. La metodología utilizada ha consistido en la revisión de 150 artículos y columnas publicadas en la prensa española en los últimos 20 años que han tratado este tema para configurar la postura del columnista, su actitud y los recursos lingüísticos que utilizan para ello. Las conclusiones obtenidas desvelan que las opiniones oscilan entre la postura más purista a la más abierta a cualquier posibilidad, pero también que, conforme avanza el tiempo, y con él la necesidad de la visibilidad de la mujer, la postura ante estos fenómenos está más cercana a la aceptación de los mismos.

Palabras clave: discurso sexista, artículo de opinión, género gramatical.

\footnotetext{
${ }^{1}$ Este trabajo se enmarca en los Proyectos I+D+i PID2019-107265GB-I00 El columnismo lingüístico en la prensa española desde sus orígenes. Análisis multidimensional, caracterización y aplicaciones (METAPRES-COLING) e I+D+i (PAIDI 2020) El discurso metalingüístico sobre "mujer y lenguaje" en la prensa española: Análisis del debate lingüístico y su repercusión social (DISMUPREN).
} 


\section{Abstract}

Sexist discourse is a recurring theme in opinion articles and in columns of the Spanish press, as it is a controversial issue and a clear carrier of ideology. The aim of this paper, from the perspective of the metalinguistic analysis of the texts, has been to identify the treatment and position of the columnists in the Spanish press before the sexist discourse; specifically, in relation to the generic masculine, to the morphological unfoldment and to the lexical duplicities. The methodology used has consisted of a review of 150 articles and columns published in the Spanish press in the last 20 years that have dealt with this issue to configure the columnist's position, their attitude and the linguistic resources they use for it. The conclusions obtained reveal that opinions range from the most purist position to the one most open to any possibility, but also that, as time progresses and with it the need for the visibility of women, the position on these phenomena is closer to acceptance of them.

Keywords: sexist speech, opinion piece, grammatical gender.

\section{El género gramatical como asunto de opinión en la prensa}

El título de este trabajo parte del concepto de género gramatical en español y de su diferenciación del de género sexual, es decir, de dos conceptos claramente delimitados en el código lingüístico del español. Ahora bien, a juzgar por cómo son tratados estos conceptos por los políticos y por los medios de comunicación y, consecuentemente, por la ciudadanía, no parece que la realidad sea así. Evidentemente, el problema conceptual de ambos deriva de lo que se ha denominado, en primer lugar, como sexismo lingüístico, es decir, de la desigualdad existente entre los hombres y las mujeres, siempre a favor de los primeros, en la realización del código lingüístico del español. Aunque sería más apropiado el sustituir esta expresión, sexismo lingüístico, por la de discurso sexista (Márquez, 2013, pp. 53-93), ya que la lengua en sí misma no es sexista, pero sí lo pueden ser los usos que de ella hagan sus hablantes, tal y como recoge la Real Academia española (RAE) en su Informe sobre el lenguaje inclusivo:

Es una evidencia irrefutable que han existido, existen y existirán mensajes sexistas e incluso textos y géneros claramente misóginos. Pero tal sexismo y misoginia no son propiedades de la lengua, sino usos de la misma. No son inherentes al sistema (no son sexismo de lengua), sino valores que adquieren en el uso a causa de la intencionalidad de los emisores o de sus prejuicios ideológicos (sexismo de discurso) No son responsabilidad del medio, sino de los hablantes. No se corrigen mejorando la gramática, sino erradicando prejuicios culturales por medio de la educación (RAE, 2020, pp. 32-33).

De esta realidad, devienen dos ideas clave que pueden considerarse como causa y consecuencia de ella, es decir, el reconocimiento de la desigualdad entre el hombre y la mujer en la sociedad española actual, respecto a la primera; y la necesidad de la visibilidad de la mujer (Bosque, 2012), en relación a la segunda, pues es en el discurso donde radican los usos lingüísticos sexistas en español.

\subsection{La naturaleza diacrónica del género en español}

Claro está que este tema no es algo aislado de la lengua española del siglo XXI, sino que es herencia de toda una tradición histórica y de la propia idiosincrasia del 
español como lengua romance. Desde un punto de vista diacrónico puede explicarse la naturaleza poco sistemática del género en español, derivada tanto de la configuración del género en latín, como, posteriormente, en la descomposición del sistema casual latino en su paso a las lenguas romances y, más concretamente, al español (Lapesa, 1964, pp. 57-59). Se simplificó la clasificación de género al conservar solo el masculino y el femenino y perder el neutro en el sustantivo (Menéndez Pidal, [1904], 1982, pp. 212-218; Rodríguez Pantoja, 2004, pp. 120121; Ariza, 2004, p. 315) que se trasvasó tanto al masculino (mancipium $>$ mancebo), como al femenino (sagma $>$ jalma), pero con muchas vacilaciones y ambigüedades, pues, por ejemplo, muchos plurales neutros pasaron a ser femeninos (folia $>$ hoja; ligna $>$ leña) (Lapesa, $1984^{9}$, pp. 70-76). Estos datos se ven reafirmados por Alvar y por Pottier (1983, p. 45) al afirmar que el género gramatical en español depende de su origen, de las analogías en su formación o de la inseguridad por la que se crean tanto masculinos y femeninos sin un rigor claro que vacilará durante siglos. Concluirán aseverando la arbitrariedad del género gramatical y cierta indiferencia ante ello. Este hecho se constata en las primeras gramáticas del español en los siglos XVI y XVII, ya que en ellas se alternaban diferentes números de género, así como diferencias en su caracterización, desde la expresión del sexo, hasta explicaciones enteramente funcionales, hechos que se han proyectado en el resto de gramáticas hasta nuestros días (Calero Fernández, 2012, pp. 20-21, p. 30).

En la actualidad, el género tiene una doble consideración gramatical, según sea esta normativa o descriptiva. Si se atiende a una normativización del género, se establece que "El género es una propiedad de los nombres y de los pronombres que tiene carácter inherente y produce efectos en la concordancia con los determinantes, los cuantificadores, los adjetivos y, a veces, con otras clases de palabras" (RAE, 2009, p. 81).

Ahora bien, la categoría gramatical del género es muy compleja y controvertida en español porque, por mucho que se quiera acudir y encontrar amparo en la gramática normativa, esta demuestra su carácter mudable y pone en evidencia el funcionamiento no sistemático de la categoría, de tal forma que "las consecuencias de tal diversidad de soluciones en la descripción de la flexión de género son múltiples y tienen que ver esencialmente con el grado de arbitrariedad o motivación del género en los nombres españoles y, en su caso, con la naturaleza semántica o formal de los factores que lo determinan" (Ambadiang, 1999, p. 4845). Por este motivo, el género no solo puede estar asociado a su forma de expresión, sino también a alguno de sus rasgos constitutivos totales, como su significado, su clase léxica, característica de sus referentes, etc. (Ambadiang, 1999, p. 4846; Morera, 2011); siendo por esta razón donde entronca y tiene lugar la problemática en la posible construcción de determinados femeninos en español, siempre en virtud de la necesidad que demuestran ciertos colectivos en la sociedad española.

\subsection{El discurso sexista en los artículos de opinión de la prensa española}

Tanto el artículo de opinión como la columna son tipos textuales periodísticos encuadrables dentro de los textos argumentativos, los cuales, mediante una estructura discursiva expositiva y argumentativa y unos recursos lingüísticos y pragmáticos, persiguen persuadir y convencer al lector sobre la tesis que defienden (Marimón Llorca, 2019; Martínez Egido, 2019a, p. 176, 2019b, pp. 79-80, 2020, pp. 402-403). Dentro de ellos, como una especie de subclase temática, estarían los 
que tratan cuestiones lingüísticas y que configuran, por tanto, un discurso metalingüístico al tratar aspectos que contravienen la norma lingüística o suponen una novedad respecto a ella (Coulmas, 2016; Marimón Llorca, 2019). Por este motivo, un tema lingüístico tan controvertido como es el uso sexista del lenguaje es lógico que sea objeto de controversia (Guerrero Salazar, 2012; Llamas Saíz, 2013) $\mathrm{y}$, por consiguiente, que se reflejen las distintas opiniones mediante artículos de opinión y columnas en la prensa española.

Los autores de estos artículos o columnas defienden una postura que abarca desde la defensa a ultranza de lo que entienden por norma lingüística o, por el contrario, se sitúan en una postura contraria, pasando por diferentes estadios intermedios (Martínez Egido, 2019a, pp. 176-177), es decir, de su punto de vista ante el purismo lingüístico, relacionado directamente con el apego a los planteamientos defendidos por la Academia durante más de 100 años de periodismo, ya que esta siempre es un argumento de autoridad esgrimido por los articulistas para autentificar su propia opinión (Martínez Egido, 2020, p. 416).

\subsection{Hipótesis de partida, objetivos y metodología}

Partiendo de la consideración de lo dicho hasta este momento, la hipótesis de partida de este trabajo es el entender que cada articulista y cada columnista se situará en una posición concreta ante las cuestiones relativas a la construcción y al uso del género gramatical en español de acuerdo con su postura ideológica respecto al purismo lingüístico y en estrecha relación con la norma propugnada por la Academia española en cada momento.

De esta forma, el objetivo del presente trabajo es identificar el tratamiento y la postura ante el hecho del discurso sexista por parte de diferentes articulistas y columnistas de la prensa española, pues los primeros pueden publicar esporádicamente en la prensa, mientras que los segundos son de aparición fija durante un tiempo determinado, entendidos como representantes de la opinión de los españoles ante este hecho lingüístico. Para ello, la metodología seguida ha consistido en observar y analizar en los medios de comunicación españoles digitales más de 150 artículos en un vasto espacio temporal, pero centrado claramente, por los ejemplos utilizados en este trabajo, en los dos últimos años (2019-2020), unos hechos lingüísticos muy relacionados entre sí que han sido y son en la actualidad muy polémicos en la sociedad: el llamado masculino genérico y una de sus consecuencias como es la duplicidad léxica, y el desdoblamiento morfológico. Para, de esta forma, poder llegar a concluir si hay una postura o posturas claras en los articulistas y en los columnistas o, al menos, una tendencia clara evolutiva en estas cuestiones en la sociedad española actual y que ellos plasman en sus escritos.

\section{Análisis. El discurso sexista en la prensa de opinión española}

Tal y como se ha enunciado, el análisis realizado se presenta atendiendo a los fenómenos lingüísticos expuestos, sabiendo que lo que atañe al discurso sexista se extiende a muchos más aspectos recogidos en la prensa de opinión desde siempre, tal y como se puede observar en (1):

1) Nada hay que objetar al empeño de los movimientos feministas en equiparar legal, económicamente a los dos sexos, lo cual es noble y justa aspiración. Pero sería contrario a la naturaleza del lenguaje que éste no reflejase aquellas diferencias [...] como correlato de pautas de comportamiento en la mujer no siempre atribuibles a la estructura de la sociedad. El creciente protagonismo femenino hace prever un 
deseable progreso en la eliminación de ciertas desigualdades sancionada por el uso lingüístico (Lorenzo, 1985).

Junto a esta idea del sucesivo progresismo o avance en el tratamiento no sexista de la lengua en (1), se encuentra una postura defendida por muchos articulistas o columnistas como es el diferenciar lo que es a todas luces discurso sexista de lo que no lo es, según ellos. Un ejemplo representativo de esta idea sería lo expuesto en (2):

2) El principal problema para mí en el tratamiento del uso sexista del lenguaje surge cuando sus defensores toman de la ideología de la "corrección política" el principio de la 'visibilidad' y lo aplican a la mujer en la lengua española; según dicho principio: lo que no se nombra no existe, por lo que el lenguaje común, el que hemos hablado siempre, es sexista al no representar a la mujer y mostrar solo al hombre. A partir de tan peregrina idea, se crea toda una oficialista 'cruzada' de ofendidas minorías a favor del "todos y todas (Cortés, 2009b).

Esta premisa, cuya no validez es defendida por Cortés, pero que se ha instalado en el imaginario social como un elemento del criterio sapiencial, es precisamente la que se reivindica como máxima por un amplio sector feminista. Por ello, el autor indica de forma clara que debe evitarse y, sobre todo, que no se debe asumir por la sociedad española, para lo que utiliza la metáfora de la oficialista cruzada para mostrar el sentimiento profundo que los mueve a ello.

\subsection{Sobre el masculino genérico y los desdoblamientos léxicos}

Bajo esta designación se entiende que "[...] la expresión no marcado alude al miembro de una oposición binaria que puede abarcarla en su conjunto, lo que hace innecesario mencionar el término marcado" (RAE, 2009, p. 85); además de que en esta misma gramática académica se haga constar el que dicho fenómeno se perciba como "[...] una tendencia reciente [...] a construir series coordinadas constituidas por sustantivos de persona que manifiesten los dos géneros: a todos los vecinos $y$ vecinas; la mayor parte de las ciudadanas y de los ciudadanos, [...]" (RAE, 2009, p. 87). Así se da por válida esta posibilidad en ciertos usos vocativos, pero destacando que: "Exceptuados estos usos, el circunloquio es innecesario cuando el empleo de género no marcado es suficientemente explícito para abarcar a los individuos de uno y otro sexo, lo que sucede en gran número de ocasiones [...]". (RAE, 2009, p. 87). Ahora bien, resaltando algunos contextos en que su uso no deje claro que el masculino plural comprende por igual a los individuos de ambos sexos como en el caso de los españoles y las españolas pueden servir en el ejército. (RAE, 2009 , p. 87). Si bien es cierto que, por otra parte, en otras gramáticas más descriptivas se reconoce que ese uso del masculino genérico oculta a la mujer tras el hombre que, de este modo, se le antepone. (Ambadiang, 1999, p. 4863)

Ahora bien, en los artículos de opinión y en las columnas se observan posturas que recorren todo el espectro posible de adhesión o rechazo al empleo del masculino genérico y, en este último caso, de asunción con una de sus posibles soluciones como es el desdoblamiento léxico. De esta forma, no siempre la posición de los articulistas es tan aparentemente conciliadora como la de la RAE consignada arriba, tal y como se constata en (3):

3) La lengua es como la piel de la sociedad; se adapta a los repliegues del cuerpo colectivo y sigue fielmente sus cambios. Es un tejido vivo que no puede modificarse por decreto: los ortopédicos tropezones de los "compañeros y compañeras" no son 
más que feísimas verrugas que, de seguir creciendo desordenadamente, terminarán por convertir nuestro cuerpo social en un deformado hombre (mujer) elefante (Montero, 2012).

Detrás del símil de que la lengua sea como la piel, se aboga por no decretar nada, sino esperar o asumir lo que el uso diga. Ahora bien, la postura de la columnista, aunque parezca comprensiva ante el fenómeno, se manifiesta claramente con la metáfora que realiza al hablar de ortopédicos tropezones para referirse a las duplicaciones y seguir con la metáfora de llegar a ser un deformado hombre (mujer) elefante. Evidentemente no está en la línea de aceptar este recurso lingüístico, pues ni tan siquiera contempla algún contexto en el que pueda ser aceptado y modaliza toda su exposición con diversas metáforas contraponiendo lo positivo de la lengua tejido vivo y feísimas verrugas.

A su vez, en (4) otra articulista va un poco más allá en sus consideraciones, pero manteniendo claramente una postura muy cercana a la opinión anterior:

4) La preocupación por el lenguaje inclusivo, ese que no generaliza a base de excluir a más del $50 \%$ de la población, me parece válida en principio. Me resulta apropiado que se hable tanto de las "personas" como de los "seres humanos"; incluso, a veces, entiendo algún que otro desdoblamiento del género para aclarar alguna ambigüedad, pero son pocas esas veces a las que me refiero y me irritan los desdoblamientos continuos por parte de quien no tiene otra intención ni otra idea que la de quedar bien dentro de los parámetros de la corrección política (Donapetry, 2020).

Su posición ante el lenguaje inclusivo está clara en la primera frase al utilizar el juego de contrarios entre lenguaje inclusivo y ese que no generaliza y excluir, si bien acepta el desdoblamiento de género en contextos ambiguos. La autora en primera persona, como es característica en este tipo textual, manifiesta sus propios sentimientos (me irritan los desdoblamientos continuos) para, incluso, adelantar una causa de ese uso directamente relacionada con la corrección política predominante.

Otro aspecto de la opinión en las columnas y artículos de la prensa versa sobre el cansancio y falta de economía lingüística que produce la constante duplicidad de género, como puede comprobarse en (5):

5) La insistente campaña duplicadora ha contribuido, sí, a formar una conciencia general. Pero incluso las más exitosas campañas publicitarias caducan algún día y son retiradas para no cansar al público y resultar contraproducentes. De hecho, la machacona duplicación del género (si fuera esporádica y más simbólica en un discurso se digeriría mejor) agota seguramente a muchas personas, y tal vez les hace pensar si no se atenta ya contra su inteligencia cuando alguien dice "los diputados y las diputadas de mi grupo"; porque todos los españoles saben que los grupos están formados por diputados y diputadas, y la duplicación parece decirles que no se han enterado (Grijelmo, 2018a).

Se revela la existencia de una campaña duplicadora en la que el articulista reconoce una intención concreta, por lo tanto promovida y no natural de la sociedad. En (5) se califica negativamente con el adjetivo machacona a la duplicación del género y se ironiza con la capacidad intelectual de aquel que necesita tal duplicidad. La modalización es completa en esta opinión y se encamina hacia la convicción de la postura del articulista en contra del desdoblamiento; pero los argumentos que utiliza no son lingüísticos estrictamente, sino ideológicos, ya que, sin aludir a la norma, se manifiesta implícitamente una postura purista ante el fenómeno denunciado. 
Es en este momento donde podría incluirse el concepto de "sexismo del oyente", tal y como se afirma en (6):

6) Muchas oyentes acusan de sexismo a muchos hablantes porque ellas interpretan como sexistas expresiones que no lo son. En tales casos, quienes son sexistas son las acusadoras y no los acusados (García Meseguer, 2006).

Este concepto formulado en (6) varía la perspectiva en el tratamiento de la cuestión, pues no sería ya tanto que la lengua fuera en sí misma sexista, sino que esa característica se incluiría en el discurso y, profundizando más, no sería necesario que el emisor así lo emitiera, sino que sería el emisor quien lo interpretara de esa manera. En este caso, todo podría ser sexista y sería una verdadera revolución lingüística el que triunfara en el uso mayoritario de la sociedad española, puesto que de momento no se da, aunque haya una fuerte presión para ello por parte de ciertos sectores sociales y políticos.

$\mathrm{Y}$, casi en el extremo opuesto se situaría la posición que condenaría el masculino genérico en función de otros procedimientos lingüísticos, como sería el caso de los desdoblamientos léxicos y que, como muestra, podría ser lo recogido en (7):

7) Sin embargo, la utilización de lenguaje no sexista por parte del feminismo no interpreta el masculino genérico como una forma de pulir y dar esplendor a la lengua que hablamos, sino como una batalla en el campo de lo simbólico. "El lenguaje enmarca", afirma Elisa G. McCausland, periodista, crítica cultural e investigadora especializada en el análisis de la cultura popular desde la perspectiva de género. El marco del masculino genérico no es neutro, explica, e invisibiliza a las mujeres. "Hay una deuda histórica con la visibilización de las mujeres. El lenguaje lo utilizas para visibilizar lo que es visible y lo que no", añade. Los dobletes, tan polémicos, servirían de experimento provocativo, como forma de poner el debate encima de la mesa (Mohorte, 2016).

Se articula en (7), mediante el argumento de autoridad y de cita, la idea de que el masculino genérico no es tal, sino que invisibiliza a las mujeres y, en virtud de paliar esa consideración, los dobletes serían una forma de exponer el problema. Se parte para ello de la misma premisa falsa constatada en (2). Es pues interesante esta idea porque se constata el hecho de dichos dobletes léxicos como herramientas para conseguir algo, pero no como un procedimiento con razonamiento lingüístico y necesario, sino plenamente sociológico; sería por tanto afirmar que la sociedad no cambia la lengua, sino que con la lengua debe cambiar la sociedad. Esta idea es recogida también por muchos articulistas, como lo presentado en (8):

8) La realidad modifica el lenguaje porque la propia realidad ya ha cambiado. Cuanto más vayamos cambiando nuestra realidad inmediata en todos los ámbitos, más inclusiva será la lengua en la que comunicamos esa realidad (Donapetry, 2020).

Así, en este sentido de que la lengua es utilizada con fines no estrictamente lingüísticos, son varias las opiniones que se registran en las columnas y en los artículos de opinión sobre este uso instrumental de la lengua a favor de intereses concretos, tal y como puede observarse en (9), en el que se denuncia este hecho, pero desde el mundo de la política:

9) La lengua española lleva mucho tiempo siendo torturada por la política, para ver si así confiesa sus culpas (Grijelmo, 2018). 
En esta necesidad de marcar la diferencia de género se ha llegado a la duplicidad de homosexual, definida en el Diccionario de lengua española en su primera acepción como "dicho de una persona: inclinada sexualmente hacia individuos del mismo sexo" y lesbiana como "Homosexualidad femenina" y que ya Lázaro Carreter denunciaba como ignorancia lingüística de los políticos, al encontrar en un Boletín oficial de la Comunidad de Madrid dicho desdoblamiento, tal y como se muestra en (10):

10) $\mathrm{Y}$ es en tal providencia donde habla "de los derechos de los homosexuales y lesbianas". No es infrecuente error, pero impensable en el autor del desmán, sin duda un selecto funcionario (Lázaro Carreter, 2002).

El articulista justifica su texto atendiendo a la etimología de la palabra homos del griego que significa "igual" y no "hombre" del latín homo. Por lo tanto, en (10) achaca tal desdoblamiento, no a la necesidad de significar la diferencia entre la homosexualidad masculina y femenina, sino a la ignorancia del funcionario en particular y de cierta parte de la sociedad en general; de ahí que, mediante el uso de los adjetivos explicativos, contraste en su descripción la calificación negativa de infrecuente error, oponiéndola a la valorativa positiva, pero irónica, de selecto funcionario.

Por tanto, tras la revisión realizada hasta este punto, puede afirmarse que las posturas ante estos hechos lingüísticos se formulan utilizando diferentes recursos lingüísticos para validar sus argumentos, atendiendo a las características constitutivas del tipo textual al que pertenecen, pues los autores son conscientes de la polémica que se desprende del tema que tratan. Entre esos recursos lingüísticos cabe destacar: el uso de metáforas en (2), (3), (6), (9), el uso del juego de contrarios en (4), el léxico valorativo en (5), la ironía en (5) y en (10), el estilo indirecto en la inclusión de citas de autoridad en (7), el uso de ejemplos en (10) o la expresión de la propia opinión mediante la primera persona en (1) y en (8).

\subsection{Sobre el desdoblamiento morfológico}

El español, como lengua romance, tiene sus propios procedimientos recogidos en su código para designar el género gramatical de los sustantivos (Ambadiang, 1999, pp. 4843-4884; RAE, 2009, pp. 81-126). Por lo tanto, cuando se crean femeninos no normativos, o incluso normativos pero inusuales, aparece la polémica sobre su aceptación y su uso, ya que unos los consideran innecesarios y no concordantes con la normativa lingüística, mientras otros piensan todo lo contrario, en aras del trasunto ideológico que comporta su creación y uso. Por ello es muy fácil que dicha confrontación se traslade a la prensa de opinión, como se constata en muchos artículos, como sería en (11), en donde su autora, partiendo de la premisa de que una lengua es convencional, constata que no todos pueden aceptar dicha máxima:

11) Que si con@, con x, o con e. Que si son las personas o las mujeres las fáciles. Que presidenta no, pero sirvienta sí... Una lengua por definición es convencional, pero cada vez que salta al debate público alguno de estos cambios no faltan quienes convocan su "esencia natural” o, peor, llaman a intervenir a la RAE (Díaz, 2018).

Esta opinión, el considerar la convencionalidad como una característica básica de la lengua, es una constante en la opinión periodística en la prensa española desde antaño, y no solo fruto de la situación político social actual, tal y como se demuestra tanto en (12) como en (13): 
12) Llegaron los autobuses al lugar donde el acto inaugural iba a celebrarse. Pregunté a una muchacha uniformada por mi lugar, y me remitió a un azafato que había un poco más adelante. Así me dijo: azafato. Nuevo estrangulamiento de la corriente respiratoria; nunca había oído tan peregrina masculinización, en cierto modo paralela la que llevó a llamar ridículamente modistos a los modistas (Lázaro Carreter, 1992).

Así, en (12), se califica de "peregrina masculinización" la creación de azafato para, más adelante, en el mismo artículo afirmar que: "Se trata de una masculinización estéticamente aberrante, aunque fuera posible desde el punto de vista morfológico" (p. 592). Su estupor lo manifiesta mediante la hipérbole: "Nuevo estrangulamiento de la corriente respiratoria". En el mismo sentido se refiere el articulista a los oficios que antes estaban asignados a un sexo y ahora son compartidos por el otro, reconociendo que están creando problemas, haciendo referencia a los casos de "fiscala o jueza de tan fea catadura". Es una manera clara de posicionarse en contra de lo que suponen ciertos desdoblamientos morfológicos para marcar de forma gráfica el femenino.

Incluso se puede ir muchísimo más atrás en el tiempo, concretamente a finales del siglo XIX y principios del XX, para encontrarnos en (13) una referencia a este tema en un artículo de Mariano de Cavia. Este periodista recoge en su columna el hecho de que a una famosa bailarina la han dado en llamar la idola; por lo que, a propósito de tal creación, apuntará:

13) Me parece muy bien, de perlas aun de brillantes, esa innovación en nuestro atrasado idioma. [...] Eso de la ídola me parece de tan sana renovación y tan elegante regeneración en el lenguaje, que juro no decir en adelante "la reo" ni "la testigo". ¡Abajo esa ranciedad común de dos! Hay que decir la rea y la testiga, para que la ídola vaya bien acompañada. [...] ¡La ídola, la rea, la testiga, la fenómena, la monstrua, la símbola... Admiremos la flexibilidad y elasticidad de este idioma sin segundo que nos deja hacer con sus palabras lo que un jugador de manos hace con un limón: sacar de él dos alpargatas y una lata de sardinas (Cavia, 1922, pp. 158159).

Aunque en principio parezca que todo el artículo está plagado de la ironía consustancial a su forma de escribir, lo cierto es que parece que es verdad que defienda esa posibilidad de desdoble de la lengua, así como el potencial de su sistema lingüístico sin entrar en cuestiones gramaticales tradicionalistas. Para ello, escribe de forma muy connotativa utilizando metáforas intensificadoras al calificar de perlas aun brillantes a estos hallazgos, el símil con el jugador de manos, así como el uso de adjetivos valorativos explicativos en atrasado idioma. Esta opinión se refuerza con lo expresado en otros artículos en donde aboga por la construcción de ese mismo tipo de femeninos (Cavia, 1922).

En (14), por el contrario, cien años después, se vuelve a poner de manifiesto la insistencia en la no necesidad de creación de ciertos femeninos:

14) No insistiré hoy sobre las pretensiones de acabar con el "lenguaje sexista". [...] En cuanto a "cancillera", "bedela", "ujiera" y otras aes innecesarias, ya que la terminación en "-er" o en "-el" rara vez indica género masculino ni femenino, a este paso se acabará exigiendo que no se diga "mujer", sino "mujera". Ustedes verán, señoras. Y señores (Marías, 2008).

De tal forma que, desarrollando lo anterior, en (15) se constata una de las eternas características en esta polémica, que no es más que el descubrir cuál es el malentendido que la origina, es decir, la eterna confusión entre género y sexo: 
15) Pero el hecho de que no exista hablante perfecto no nos exime de intentar hablar conforme a la norma culta. Es un deber, acaso moral, hacia nuestra lengua madre. Una de las cosas primigenias sería saber distinguir entre sexo y género. Las palabras no tienen sexo, que es cosa de animales. No de las palabras que significan a los animales. Las palabras no son las cosas que representan. Las palabras son sonido adherido a significados. El género de los objetos es arbitrario. Varía de una a otra lengua. Y aun dentro de la misma lengua. El sexo, por lo menos el asignado según el aparato reproductor, es de los seres vivos (Delgado, 2017).

El articulista aboga por el hecho de que existe una norma culta y que debe ser respetada, modalizando el uso al utilizar una metáfora como un deber hacia nuestra lengua madre. Llega a afirmar en (15) que las palabras no son las cosas que representan, que siendo cierto, su significado adherido es lo que les propicia la entidad en el pensamiento colectivo. Es decir, hace un planteamiento estrictamente lingüístico o gramatical sin entrar en lo que las palabras en su uso pueden representar e identificar. Esta postura sería representante de todas aquellas opiniones que se fundamentan en la palabra en sí como algo aislado del uso, que será, precisamente, lo que otros articulistas defiendan. Este sería el caso de (16), al crear, incluso, un morfema neutro (-e) para evitar esa diferenciación entre masculino y femenino, al menos en su primer momento de andadura:

16) $Y$ es que el género gramatical es una de las grandes fallas lingüísticas activas del español. Desde hace tiempo, distintos colectivos de hablantes ven limitante y conflictivo el uso convencional del masculino y el femenino y proponen formas de disidencia gramatical. El género neutro en -e (todes) es el último episodio en la sucesión de enmiendas y reformulaciones en torno al género gramatical que han surgido en el español de las últimas décadas (Álvarez Mellado, 2017).

La necesidad de crear femeninos que, en principio, no seguirían la llamada norma culta en su formación es un hecho que, aunque el tiempo y el uso han demostrado baladíes, aun hoy en día siguen generando polémica, como sería el caso consignado en (17), que da fe de esta cuestión por parte de ciertos políticos:

17) Al parecer hay en el Senado una pequeña pendencia entre su presidenta y un grupo de senadores de Vox acerca de la forma en que han de dirigirse a ella; la primera quiere ser llamada "presidenta"; los segundos, erre que erre, insisten en decirle "señora presidente" (Picatoste, 2020).

Esta polémica con el femenino de presidente, que, en principio, se lograría con la combinación de los artículos masculinos o femeninos, pues es común en cuanto al género, sigue estando en la calle, a pesar de que ya en el Diccionario panhispánico de dudas de 2005 se dijera que "[...] el uso mayoritario ha consolidado el femenino específico presidenta". Esta palabra es un claro ejemplo de que recurrir a la norma para justificar o no justificar una formación en femenino no es un argumento válido para no autentificar su posible validez; ya que, por ejemplo, sirvienta, tendría la misma formación en femenino que presidenta, pues ambas voces provienen de un participio presente latino -ns/-ntis, sin marca de género femenino ni masculino, y que ya aparece recogida en el Corpus diacrónico del español, CORDE, en 1260.

En definitiva, son varias las opiniones que, aceptando la formación de los femeninos si estos son necesarios y normativos, están en contra de crear vocablos femeninos por la obligación políticamente correcta de tener que crearlos. Pero hay voces autorizadas que, reconociendo el problema de la norma, apelan a las 
posibilidades de formación que ofrece el sistema lingüístico como herramienta para dicha creación, como puede leerse en (18):

18) Un resumen de lo hasta aquí expuesto, sería aconsejar que, cuando se presente un problema en la formación de un femenino de profesión, lo mejor es atenerse al sistema, ya que la norma è mobile (Gutiérrez Ordóñez, 2018).

No obstante, es mayoritaria la opinión de los columnistas pertenecientes al ámbito académico que, si bien aceptan unos femeninos, parece que no otros, como se puede apreciar en (19), en donde también se acude sin nombrarlo al concepto de "sexismo del oyente" recogido anteriormente:

19) La lengua, sin duda, evoluciona al mismo tiempo que cambia la sociedad; por ejemplo el papel de la mujer ha hecho que hablemos de arquitectas, de registradoras, de abogadas, de ingenieras o de obreras de la construcción (aunque no tenga sentido hacerlo de jueza, fiscala o alfereza, como tampoco de futbolisto o ebanisto). El error está en confundir esa sociedad con las convenciones del código lingüístico en que nos comunicamos; estas no son reflejo de esta ni de ninguna otra sociedad. Si olvidamos esto, tenemos todas las papeletas para ver discriminación donde no haya (Cortés, 2009).

Además de lo mostrado hasta ahora, también se encuentran las opiniones sobre este mismo tema que van más allá de lo estrictamente lingüístico y entran ya en terrenos políticos. De esta forma, la posición de cada uno de los españoles ante esta cuestión puede verse, en cierta medida, coartada en su libertad de expresión, ya que su opinión al respecto siempre puede llegar a ser interpretada como antifeminista, tal y como se recoge en (20), donde se llega a identificar la defensa del español con la no aceptación de la causa feminista mediante la metáfora de la lucha y del enfrentamiento; así como en (21) para quienes se puede defender la lengua en su integridad y ser feminista:

20) El feminismo de hombres y mujeres que obran de buena fe ha progresado a costa del lenguaje, porque sus reivindicaciones constituyen un fin superior que no debe detenerse ante daños secundarios que ni causan víctimas ni son irreversibles. Y realmente no se pueden equiparar la protesta ante el abuso del feminismo en tal o cual palabra y la lucha frente a los maltratos, las vejaciones, la discriminación, la ocultación o los salarios que sufren las mujeres.

Así pues, situarse en la defensa del idioma supone, en la práctica, enfrentarse a la causa feminista (Grijelmo, 2018a).

21) Quizá resuman todo lo dicho hasta aquí las palabras escritas por Aguas Vivas Catalá y Enriqueta García Pascual: "Se puede ser feminista sin destrozar el lenguaje. Pero difícilmente se puede evitar un uso sexista de la lengua sin ser feminista".

Y también lo que defiende la profesora feminista María Ángeles Calero, partidaria de que se deshaga desde la escuela la falsa relación entre género y sexo: El género se debe considerar como un mero accidente gramatical (Grijelmo, 2018b).

Tanto en (20) como en (21) el mismo articulista en dos de sus trabajos manifiesta esa idea de que criticar el retorcimiento del lenguaje a favor de la causa feminista califica a quien lo hace de antifeminista, cuestión que no es cierta en absoluto. Este es uno de los riesgos que los columnistas corren cuando se identifica en la sociedad el uso de determinados recursos, como la creación de femeninos forzados, con la defensa del feminismo en sí. Por este hecho puede ser que sean atacados o estigmatizados por los que piensan lo contrario, sobre todo por ciertos colectivos sociales y políticos. 
Objetivando las diferentes posturas, puede servir la posición de la RAE, expresada en su informe solicitado por el Gobierno para una nueva redacción de la Constitución española desde la visión que exige, según él, el lenguaje inclusivo, para observar y delimitar cuál puede ser ahora mismo la posición mayoritaria entre los articulistas y comentaristas de opinión en la prensa española. Sería la expresada en (22):

22) No hay, pues, razones gramaticales ni de inteligibilidad semántica que obliguen a modificar la redacción.

No obstante esta valoración general, el informe considera que es aconsejable una posible reforma, cuando proceda, para adecuar la redacción de algunos preceptos a las realidades de hoy y a los correspondientes usos lingüísticos más generalizados. Tal es el caso de las voces y expresiones relacionadas con el matrimonio, las relaciones de pareja, las relaciones entre padres e hijos, la discapacidad o la incorporación de denominaciones en femenino como Princesa de Asturias (RAE, 2020, p. 2).

Es decir, se reconoce cierta necesidad de cambio que adapte la redacción de dicho texto a las realidades sociales actuales, pero en temas concretos y no como una norma nueva generalizadora.

De ahí pueden explicarse ciertas opiniones en la prensa que se van alejando de posiciones más o menos tajantes que se defendían no hace mucho tiempo, y se van aproximando mucho más a una aceptación en función de la necesidad que el uso lingüístico revela, tal y como sería el caso de los dos textos siguientes (23) y (24):

23) La solidaridad al contemplar los problemas de la mujer lleva a muchos ciudadanos a decir "la jueza" y "las juezas". Esa $a$ que marca el femenino no añade información, pero denota la intención ideológica de fondo; y es comprensible (Grijelmo, 2018a).

24) Cada hispanohablante se formará sus opiniones personales a partir de esa detallada exposición de la Academia. Ahora bien, lo decisivo en este conflicto no consiste en que cada cual pueda adoptar su propia gramática en uso de su libertad indiscutible, por supuesto, sino en observar cómo casi 600 millones de hablantes aplican una forma común de expresarse sin que nadie se haya dedicado a ponerlos de acuerdo (Grijelmo, 2020).

Si en el primero, (23), se admite esa formación femenina como algo ideológico que, socialmente, podía entenderse, en el caso de (24) ya se acepta lo dicho por la institución académica sin entrar en matices sociológicos ni de ningún tipo; pero, claro está, se apela al sentido generalista en el uso de la lengua que debe ser una característica de todos sus hablantes. Por ello puede afirmarse que, cada vez, las posturas en la prensa española están más a favor de que se consoliden estos fenómenos mediante el uso lingüístico, más que con que se esgrima el puro argumento normativo gramatical. En consonancia con esto último iría la postura ya más transigente y acorde con los tiempos, recogida en (25), pues con ella se vislumbra el camino de lo que será en un futuro el género gramatical en español, sobre todo tras la posición de la Academia al respecto:

25) La tricentenaria institución ha corregido en los últimos años definiciones machistas; ha modificado ejemplos discriminatorios en las acepciones; se han abierto paso los femeninos innovadores... y ahora podemos encontrar marcas de aviso sobre el sentido despectivo de algunos términos que antes se mostraban como si tuvieran un valor objetivo. 
Y ello ha ocurrido por al menos tres razones: la propia convicción de quienes integran la docta casa, la presencia de mujeres en la institución y la presión eficaz del feminismo. Conviene celebrar todo eso, aunque a cambio tengamos que prescindir del extraordinario placer que a cualquiera nos produce criticar a la Academia y acusarla de retrógrada (Grijelmo, 2020).

La presión del feminismo, como se indica en (25), y con ella el cambio en la sociedad española, es y será la que marque el uso lingüístico para que el discurso en español deje de ser sexista y, para ello, se tendrá que ir adecuando todo el sistema comunicativo del español.

Al igual que sucediera en el apartado anterior de este análisis, los articulistas muestran sus posturas, también variadas y en ocasiones enfrentadas, y para la exposición de sus argumentos, y con ello modalizar sus escritos, emplean diferentes recursos lingüísticos para conseguir sus objetivos, tales como la construcción de metáforas en (12), (13), (15), (16), (19) y (20); el humor y la ironía en (17) y (18); la hipérbole en (14); la oralidad en (11) y el argumento de autoridad en (21), (22), (23), (24) y (25); siempre en consonancia con el tipo textual que practican.

\section{Conclusiones}

Sin duda alguna, el discurso sexista posee las características necesarias para ser tratado por los articulistas y los columnistas en la prensa española. En él se plantea una determinada posición ideológica del autor respecto a la norma lingüística del español en los elementos que analiza en sus textos.

Se ha comprobado que no hay unanimidad en la posición que adoptan los articulistas ante los elementos lingüísticos contemplados en el discurso sexista, es decir, en lo concerniente al masculino genérico, a los desdoblamientos morfológicos y a las duplicidades léxicas, por lo que se confirma nuestra hipótesis de partida. Lo mismo ocurre con el objetivo perseguido, pues se ha podido comprobar, mediante la metodología descrita y aplicada, diferentes tratamientos de los fenómenos, así como diversas posturas ante ellos. El punto de partida de la polémica es la propia configuración diacrónica del género gramatical en español, heredero de la transformación de la categoría latina, que no es sistemática y que se va adaptando a las diferentes creaciones en función de las necesidades de los hablantes. A ello se añaden dos cuestiones que potencian la polémica sobre el género: la primera es partir de la premisa de que lo que no se nombra no existe; y la segunda es la continua y directa relación entre género gramatical y sexo. Ambas son asumidas en diferente grado por los columnistas, siempre en función de su propia ideología lingüística.

Por tanto, en la defensa del masculino genérico, o de su condena mediante los desdoblamientos morfológicos, y también de la necesidad o no de crear duplicidades léxicas en torno al femenino, los articulistas, tal y como se ha señalado, se mueven según dos guías; es decir, los que abogan por que la lengua tiene una tradición y una gramática que habría que respetar, y por los que no tienen en cuenta nada de eso, sino que se mueven por la defensa de la causa feminista, en virtud de que se cumpla la total visibilidad de la mujer. Quizá, lo que los aúna a todos en el fondo y en un corto espacio temporal es el hecho de cómo funciona la lengua, ya que siempre su desarrollo se produce en función del uso que de ella se necesite; mientras que la discrepancia en la actuación estaría en promover acciones para acelerar ese proceso que, de nuevo, el uso terminaría por imponer.

Al hilo de esas consideraciones generales y conclusivas y con el uso de diferentes recursos lingüísticos ya señalados, se plantean en cada uno de los 
artículos de opinión diferentes argumentos que favorecen o niegan las tesis enfrentadas. De esta forma, respecto al primer fenómeno, el masculino genérico, salvo los que defienden a toda costa su no utilización a favor de los desdoblamientos morfológicos, se acepta el que en determinados contextos que puedan resultar ambiguos se utilice, pero en el resto no se permita. En este caso se alude al principio de economía lingüística que pueda favorecer la lectura y la comprensión de los textos. Sin embargo, en el caso de los desdoblamientos léxicos en cuanto al género, cada vez se está más lejos de esgrimir el argumento de la norma del castellano en la construcción de femeninos atendiendo a su propia diacronía, en función de las necesidades que la propia sociedad exija. Y aquí habría un elemento importante que se constata en las columnas más cercanas al presente y es decantarse hacia posturas más comprensivas en la construcción de determinados femeninos a medida que también se manifiesta en este sentido la Academia Española; es decir, los puristas van dejando de serlo también al compás del no purismo académico que se hace más patente cada día.

Por lo tanto, podría decirse que, como siempre ha ocurrido, si cambia la realidad, la lengua cambiará con ella y eso se aplicará a los cambios sociales que se produzcan en torno a la mujer en la sociedad. En los artículos analizados ya se observa y se comprueba en muchos de ellos esta circunstancia aplicada al discurso sexista: si la realidad social de la mujer cambia, la realidad lingüística cambiará inevitablemente con ella, de ahí la atenuación en muchas de las opiniones. Será, por tanto, objeto de otros trabajos posteriores el observar si la prensa de opinión española sigue teniéndose que ocupar de estas cuestiones o, por el contrario, ya habrán dejado de ser objeto de polémica.

\section{Referencias}

\section{Referencias primarias}

1. Álvarez Mellado, E. (2017). Todas, todas, todxs, todes: historia de la disidencia gramatical. El Diario.es, 27-06-2017. Recuperado de:

https://www.eldiario.es/opinion/zona-critica/todas-todes-historia-disidenciagramatical_129_3307468.html [última consulta: 14-10-2020].

2. Casas Carbajo, J. (2017). La perversión y el mal uso del lenguaje. La Voz de Cádiz. Recuperado de https://www.lavozdigital.es/opinion/lvdi-perversion-y-lenguaje201710061316_noticia.html?ref=https:\%2F\%2Fwww.google.com [Última consulta: 14-10-2020].

3. Cavia, M. de (1922). La ídola. En Cavia, Mariano de, Limpia y fija (pp. 158-159). Madrid, Renacimiento.

4. Cortés, L. (2009a). Género y sexo (I). La voz de Almería, 14-09-2009.

5. Cortés, L. (2009b). Género y sexo (III). La voz de Almería, 28-09-2009.

6. Coulmas, F. (2016). Guardians of Language: Twenty Voices Trough History. Oxford, OUP. DOI: https://doi.org/10.1093/acprof:oso/9780198736523.001.0001

7. Delgado, S. (2018). La gramática siempre pierde. La Opinión de Murcia, 13-02-2018. Recuperado de: https://www.laopiniondemurcia.es/opinion/2018/02/13/gramaticapierde/897738.html [Última consulta: 14-10-2020].

8. Díaz, A. (2018). Lengua inclusiva: el episodio lingüístico del debate de género, Ideas de Izquierdas, 24-06-2018. Recuperado de:

https://www.laizquierdadiario.com/Lengua-inclusiva-el-episodio-linguistico-deldebate-de-genero [Última consulta: 14-10-2020].

9. Donapetry, M. (2020). El lenguaje inclusivo. El periódico de Extremadura, 13-022020. Recuperado de:

https://www.elperiodicoextremadura.com/noticias/opinion/lenguajeinclusivo_1217971.html [Última consulta: 14-10-2020]. 
10. García Meseguer, Á. (2006). El sexismo del oyente. El País, 14-12-2006. Recuperado de: https://elpais.com/diario/2006/12/14/opinion/1166050808_850215.html [Última consulta: 18-10-2020].

11. Grijelmo, Á. (2020). La Academia progresa. El País, 27-01-2020. Recuperado de: https://elpais.com/cultura/2020/01/27/actualidad/1580155562_815274.html [Última consulta: 19-10-2020].

12. Grijelmo, Á. (2018a). El lenguaje lo sufre todo. El País, 09-09-2018. Recuperado de: https://elpais.com/elpais/2018/02/09/opinion/1518197386_243671.html

[Última consulta: 19-10-2020).

13. Grijelmo, Á. (2018b). No es sexista la lengua, sino su uso. El País, 23-02-2018. Recuperado de:

https://elpais.com/cultura/2018/02/23/actualidad/1519389008_808351.html [Última consulta: 14-10-2020].

14. Gutiérrez Ordóñez, S. (2018). Sobre pilota, portavoza, miembra y otros femeninos. El Mundo, 10-02-2018. Recuperado de:

https://www.elmundo.es/espana/2018/02/10/5a7df963ca474179478b4698.html [Última consulta: 19-10-2020].

15. Lázaro Carreter, F. (2002). Con algún género de dudas. El País, 03-03-2002. Recuperado: https://elpais.com/diario/2002/03/03/opinion/1015110007_850215.html [Última consulta: 23-10-2020].

16. Lázaro Carreter, F. (1992). Cónyuges y oficios nuevos, en Lázaro Carreter, F. El dardo en la palabra (pp. 590-593). Barcelona: Círculo de lectores.

17. Lorenzo, E. (1985). La mujer y el lenguaje. $A B C, 17-10-1985$, p. 3. DOI: https://doi.org/10.1002/j.2048-7940.1985.tb00456.x

18. Marías, J. (2008). No esperen por las mujeras. El País. Recuperado de: https://elpais.com/diario/2008/05/11/eps/1210487217_850215.html [Última consulta: 23-10-2020].

19. Mohorte, A. P. (2016). Ellos, ellas y la RAE: el debate del sexismo y el lenguaje. Magnet, 29-01-2016. Recuperado de: https://magnet.xataka.com/en-diez-minutos/ellos-ellasy-la-rae-el-debate-del-sexismo-y-el-lenguaje [Última consulta: 14-10-2020].

20. Montero, R. (2012). Todos y Todas. El País, 06-03-2012. Recuperado de: https://elpais.com/elpais/2012/03/05/opinion/1330951227_921857.html

[Última consulta: 02-10-2020].

21. Picatoste, J. (2020). Presidente, presidenta. El faro de Vigo, 15-03-2020. Recuperado de:https://www.farodevigo.es/opinion/2020/03/15/presidentepresidenta/2263051.html [Última consulta: 21-10-2020].

Referencias secundarias

1. Alvar, M. y Pottier, B. (1983). Morfología histórica del español. Madrid, Gredos.

2. Ambadiang, T. (1999). La flexión nominal. Género y número, en Bosque, I. y Demonte, V. (Coords.) Gramática descriptiva de la lengua española (Vol. 3, pp. 4843-4913). Madrid, Espasa.

3. Ariza, M. (2004). El castellano primitivo: los documentos, en Cano, Rafael (Coord.), Historia de la lengua española (pp. 309-324). Barcelona, Ariel.

4. Bosque, I. (2012). Sexismo lingüístico y visibilidad de la mujer. Recuperado de: https://www.rae.es/sites/default/files/Sexismo_linguistico_y_visibilidad_de_la_ mujer_0.pdf [Última consulta: 5-10-2020]

5. Calero Fernández, M. Á. (2012). La teorización del género gramatical y su aplicación a la enseñanza de ELE, en San Vicente, F. y Calero Vaquera, M. ${ }^{a}$ L. (Eds.) Discurso de género y didáctica. Relato de una inquietud Bologna-Córdoba, CLUEBUniversidad de Córdoba.

6. Guerrero Salazar, S. (2012). El lenguaje desde la perspectiva de género, en Suárez Ojeda, M. (Ed.), Género y mujer desde una perspectiva multidisciplinar (pp. 61-77). Madrid, Fundamentos.

7. Lapesa, R. (1984). Historia de la lengua española. Madrid, Gredos.

8. Lapesa, R. (1964). Los casos latinos: restos sintácticos y sustitutos en español. Boletín de la Real Academia Española, T. XLIV, C. CLXXI (enero-abril 1964) y Boletín de la Real Academia Española, T. XCIV, C CCCX, (julio-diciembre 2014), pp. 56-105. Recuperado de: http://revistas.rae.es/brae/article/view/91 [Última consulta: 18-10- 
2020).

9. Llamas Saíz, C. (2013). La actitud ante la lengua en el discurso de la prensa española: léxico y argumentación a propósito del sexismo lingüístico, en Llamas Saíz, C., Martínez Pasamar, C. y Casado Velarde, M. (Eds.), Léxico y argumentación en el discurso público actual (pp. 187-208), Frankfurt, Peter Lang.

10. Marimón Llorca, C. (2019). Las CSL como tradición discursiva metalingüística, en Marimón Llorca, C. (Ed.), El columnismo lingüistico en España desde 1940 (pp. 105131). Madrid, Arco Libros.

11. Márquez, M. (2013). Género gramatical y discurso sexista. Madrid, Síntesis.

12. Martínez Egido, J. J. (2020). Lo académico como argumento de autoridad en las columnas sobre la lengua (CSL) en su tradición discursiva, en López, S., Araceli, Carmona Yanes, E. y Del Rey Quesada, S. (Eds.): Tradiciones discursivas y tradiciones idiomáticas en la historia del español moderno (pp. 461-419). Frankfurt, Peter Lang.

13. Martínez Egido, J. J. (2019a). Lo académico como argumento de autoridad: perspectiva ideológica de los columnistas ante la norma académica", Marimón Llorca, C. y Santamaría Pérez, I. (Eds.) Ideologías sobre la lengua y medios de comunicación escritos. El caso del español (pp. 175-192). Berlín, Peter Lang.

14. Martínez Egido, J.J. (2019b). Las CSL como discurso argumentativo: el caso del mal hablante, en Marimón Llorca, C. (Ed.), El columnismo lingüístico en España desde 1940 (pp. 79-104). Madrid, Arco Libros.

15. Menéndez Pidal, R. (1904, reimp. 1982). Manual de Gramática histórica española. Madrid, Espasa-Calpe.

16. Morera, M. (2011). El género gramatical en español desde un punto de vista semántico. Frankfurt, Peter Lang.

17. Real Academia española (2020). Informe de la Real Academia española sobre el lenguaje inclusivo y cuestiones conexas. Recuperado de:

https://www.rae.es/sites/default/files/Informe_lenguaje_inclusivo.pdf [Última consulta: 19-10-2020).

18. Real Academia española (2009). Nueva gramática de la lengua española (Morfología, Sintaxis 1). Madrid, Espasa.

19. Real Academia española y Asociación de Academias de la Lengua española (2005).Diccionario panhispánico de dudas. Madrid, Santillana. Disponible en: https://www.rae.es/dpd/ [Última consulta: 21-10-2020]

20. Real Academia española, Banco de datos (CORDE) [en línea]. Corpus diacrónico del español. Disponible en: http://www.rae.es [Última consulta: 28-10-2020].

21. Rodríguez Pantoja, M. (2004). El latín hablado en Hispania hasta el siglo V. En Cano, R. (Coord.), Historia de la lengua española (pp. 107-131). Barcelona, Ariel. 